Vol. 5 No. 1 (Januari 2022), Halaman: $53-62$ Available Online at http://ejurnal.ubharajaya.ac.id/index.php/Jabdimas

\title{
Optimalisasi Pemanfaatan Sistem Informasi Pada UMKM Beladies Laundry Kiloan
}

\author{
Triyadi ${ }^{1}$, Fauzan Natsir ${ }^{1, *}$, Ni Ketut Pertiwi Anggraeni ${ }^{1}$ \\ ${ }^{1}$ Fakultas Teknik dan IImu Komputer; Universitas Indraprasta PGRI; TB Simatupang JI Nangka \\ Raya No 58 C, RT 5/ RW 5 Kecamatan Jagakarsa Jakarta Selatan; Telp. 0217818718; e-mail: \\ triyadi170@gmail.com, fauzan.natsir@gmail.com, niketutpertiwi@hotmail.com \\ * Korespondensi: e-mail: fauzan.natsir@gmail.com
}

Submitted: 05/01/2022; Revised: 12/01/2022; Accepted: 19/01/2022; Published: 31/01/2022

\begin{abstract}
Laundry business is a business that is engaged in laundry services. In the midst of busy activities, laundry is an alternative to washing clothes which is currently being used by many people, especially by urban residents. With so many customers' interest in utilizing the laundry business, laundry business actors have expanded their business by providing kilo washing and dry cleaning services. Utilization of Information and Communication Technology (ICT) is currently growing rapidly so that many business sectors of the community need it to facilitate the operation of their activities, one of which is the laundry business. The Community Service Implementation Team of Universitas Indraprasta PGRI offers an information system based on Rapid Application Development (RAD) that can be used by Beladies Laundry Kiloan business actors to make it easier for business actors and their employees to record transactions so as to minimize data loss that can cause losses. So, there is a need for training in the use of the information system offered so that Beladies Laundry Kiloan employees can optimize the use of the information system.
\end{abstract}

Keywords: Information, Laundry, System, Technology

\begin{abstract}
Abstrak
Usaha laundry merupakan bidang usaha yang bergerak di bidang jasa pencucian pakaian. Di tengah sibuknya kegiatan, laundry menjadi salah satu alternatif mencuci pakaian yang saat ini sangat dimanfaatkan banyak orang, terutama oleh warga perkotaan. Dengan banyaknya minat pelanggan dalam memanfaatkan usaha laundry, membuat para pelaku usaha laundry melebarkan usahanya dengan menyediakan layanan cuci kiloan serta dry clean. Pemanfaatan Teknologi Informasi dan Komunikasi (TIK) saat ini sudah semakin pesat sehingga banyak sektor usaha masyarakat memerlukan hal tersebut untuk mempermudah operasional kegiatannya, salah satu oleh usaha laundry. Tim Pelaksana Pengabdian Kepada Masyarakat Universitas Indraprasta PGRI menawarkan suatu sistem informasi berbasis Rapid Application Development (RAD) yang dapat digunakan oleh pelaku usaha Beladies Laundry Kiloan untuk memudahkan pelaku usaha dan karyawannya dalam pencatatan transaksi sehinga dapat meminimalisir kehilangan data yang dapat menyebabkan kerugian. Maka, perlu adanya pelatihan dalam penggunaan sistem nformasi yang ditawarkan agar karyawan Beladies Laundry Kiloan dapat mengoptimalisasikan penggunaan sistem informasi tersebut.
\end{abstract}

Kata kunci: Informasi, Laundry, Sistem, Teknologi 


\section{Pendahuluan}

Keberadaan dan peran Usaha Mikro Kecil dan Menengah (UMKM) dapat meningkatkan kesejahteraan masyarakat, karena mampu memenuhi kebutuhan ekonomi keluarga, mampu mengurangi pengangguran dan mampu memenuhi kebutuhan masyarakat yang memproduksi berbagai jenis kebutuhan pada kios pelaku UMKM (Undari \& Lubis, 2021). Dalam keberadaannya terdapat pula faktor penghambat dalam menjalankan sektor pelaku usaha mikro, kecil dan menengah (UMKM) seperti masalah permodalan dan kurangnya bahan baku yang berkualitas (Nurul Fitriana, Noor, \& Hayat, 2014).

Laundry adalah suatu jenis usaha yang bergerak di bidang jasa cuci dan seterika (Anonim, 2015). UMKM Beladies Laundry Kiloan yang terletak di Ciracas, Jakarta Timur, menjadi salah satu UMKM yang memiliki pelanggan cukup banyak. Letaknya yang berada di sekitar pabrik dan perkantoran membuat Beladies Laundry Kiloan telah memiliki pelanggan tetap dari para karyawan pabrik yang tinggal di sekitar Ciracas. Namun sayangnya, pencatatan transaksi yang terjadi pada Beladies Laundry Kiloan masih dalam bentuk konvensional dimana transaksi dicatat manual dalam nota saja. Hal ini membuat pemilik usaha kesulitan dalam merekap pendapatan dan pengeluaran. Selain itu, pencatatan secara manual pada kertas. Nota juga beresiko hilang. Maka dari itu, diperlukan sistem informasi yang membantu pencatatan transaksi secara aman dan cepat.

Pemanfaatan Teknologi Informasi dan Komunikasi (TIK) saat ini sudah semakin pesat sehinga banyak sektor usaha masyarakat memerlukan TIK untuk mempermudah operasional kegiatannya. Sistem informasi merupakan produk dari pengembangan TIK dalam bentuk program aplikasi komputer yang mencatat dan merekam data untuk mempermudah user atau pengguna dalam mengakses kembali dan mengolah data tersebut. Sistem juga didefinisakan sebagai suatu gabungan dari komponen-komponen yang saling bekerja dan berhubungan untuk tujuan tertentu (Rian \& Fuandytama, 2019). Pengertian tersebut juga dikonfirmasi oleh Hanif Al Fatta (2007), yang menyatakan sistem sebagai kumpulan dari unsur atau variabel-variabel yang saling terorganisasi, berinteraksi, dan bergantung satu sama lainnya. Sistem memiliki unsur masukan (input), pengolahan (processing), dan luaran (output) (Scott dalam AL Fatta, 2007).

Adanya perkembangan sistem informasi memberikan banyak manfaat pada pelaku usaha di antaranya pencatatan data lebih aman serta proses pengolahan data juga lebih cepat dan efesien. Untuk mendapatkan manfaat dari sistem informasi secara maksimal, maka diperlukan kemampuan pengguna atau user yang diperankan oleh karyawan dalam mengoperasikan komputer maupun sistem tersebut. Perkembangan dari kemampuan menggunakan komputer atau menjalankan sistem informasi akan menyebabkan perubahan ada metapora karyawan dalam memandang dan berinteraksi dengan komputer sehingga mengubah posisi karyawan dari yang hanya sebagai user atau pengguna saja menjadi end user computing atau pengguna yang menyelesaikan tanggung jawab dengan computer based solution secara tepat (Widarno, 2008). 
Pada tahun 2018, Yasin merancang sistem informasi berbasis web pada Pelangi Laundry Kisaran dengan menggunakan Rational Unified Process (RUP) sehingga memudahkan pihak pelangi laundry dalam menyusun laporan yang dibutuhkan seperti data pelanggan dan cucian masuk (Simargolang \& Nasution, 2018). Begitupun pada penelitian Susanto et al (2019) sistem informasi laundry dilakukan dengan berbasiskan Android sehingga konsumen dimudahkan karena dapat mengaksesnya melalui telepon selular.

Maka dari itu, Tim Pelaksana Pengabdian Kepada Masyarakat Universitas Indraprasta PGRI menawarkan suatu sistem informasi berbasis Rapid Application Development (RAD) yang dapat digunakan oleh pelaku usaha Beladies Laundry Kiloan untuk memudahkan pelaku usaha dan karyawannya dalam pencatatan transaksi dan juga perlu adanya pelatihan dalam penggunaan sistem informasi yang ditawarkan agar karyawan Beladies Laundry Kiloan dapat mengoptimalisasikan penggunaan Sistem Informasi tersebut. Menurut Sarosa, (2017), menyatakan bahwa "Rapid Application Development (RAD) adalah salah satu metodologi yang pertama kali muncul menjawab masalah kelambatan penyelesaian pengembangan sistem informasi pada SDLC konvensional". Menurut Sukamto (2018) menjelaskan bahwa "Rapid Application Development (RAD) adalah model proses pengembangan perangkat lunak yang bersifat inkremental terutama untuk waktu pengerjaan yang pendek". Adapun tujuan yang ingin dicapai dalam program ini adalah a) Memperkenalkan aplikasi sistem informasi untuk mencatat transaksi pada UMKM Beladies Laundry Kiloan; b) Pelatihan Optimalisasi Pemanfaatan Sistem Informasi pada UMKM Beladies Laundry Kiloan.

\section{Metode Pelaksanaan}

Dalam pelaksanaan kegiatan Pengabdian Masyarakat ini, terdapat beberapa tahap pelaksanaan sebagai berikut:

\subsection{Tahap Pra Pelaksanaan Kegiatan}

Pada kegiatan ini, tim abdimas membagikan kuesioner kepada pemilik usaha Beladies Laundry Kiloan terhadap proses dan alur kegiatan usaha. Fungsi dari kuesioner ini adalah untuk menganalisis efesiensi dari sistem yang sekarang ini sedang berjalan.

\subsection{Tahap Pelaksanaan Kegiatan}

Kegiatan abdimas akan dilaksanakan melalui zoom meeting dengan waktu yang disepakati bersama dengan mitra abdimas. Pelaksanaan kegiatan dilakukan dalam beberapa tahapan, diantaranya: a) Perkenalan tim abdimas dan sosialisasi tahapan kegiatan; b) Penjelasan tentang sistem informasi transaksi laundry; c) Penyampaian materi pelatihan; d) Praktik dan simulasi penggunaan sistem informasi transaksi laundry; e) Refleksi bersama antara peserta dengan tim abdimas mengenai pelaksanaan kegiatan. 


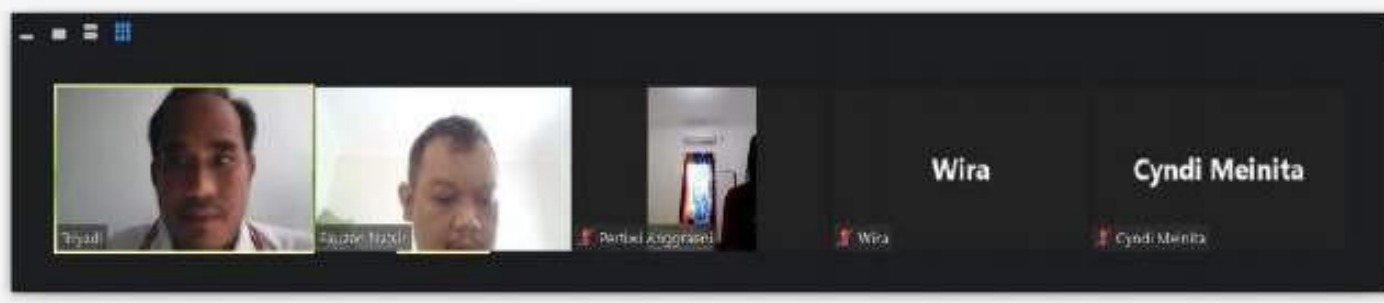

\title{
Optimalisasi Sistem Informasi Laundry Beladies
}

\author{
- - \\ Abdimas
}

Sumber: Hasil Pelaksanaan (2021)

\section{Gambar 1. Checking Virtual Room}

Pada kesempatan pelatihan ini, materi yaitu tentang optimalisasi penggunaan sistem informasi pada UMKM Laundry disampaikan. Selain memberikan pemahaman tentang materi, contoh penerapannya juga diberikan langsung dengan praktik secara virtual. Pelaksanaan pelatihan dimulai dengan memberikan penjelasan dan pemahaman pentingnya menggunakan sistem informasi, bagaimana menggunakannya dan apa saja yang bisa didapat dari sistem informasi ini. Peserta terlihat antusias dan menanyakan bagaimana proses penggunaan sistem informasi tersebut.

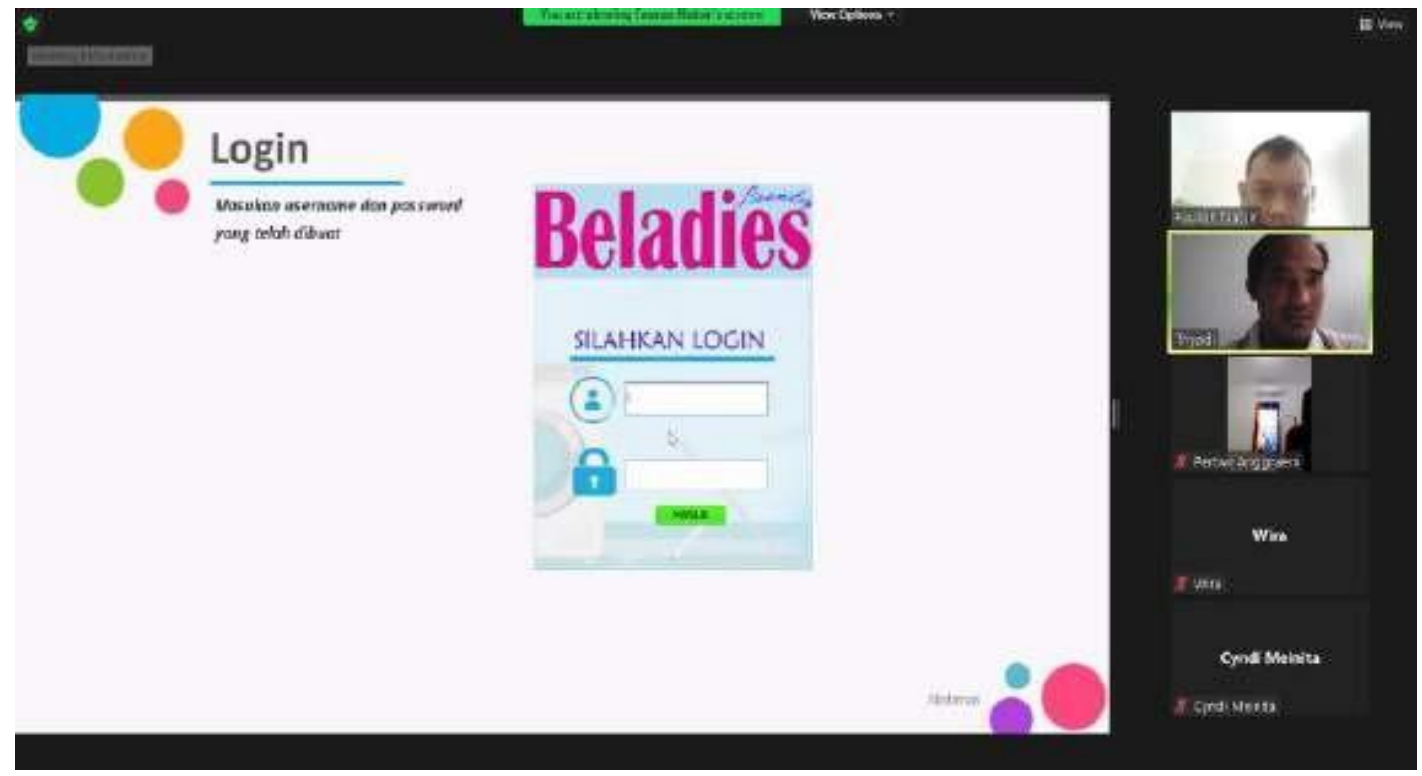

Sumber: Hasil Pelaksanaan (2021)

Gambar 2. Materi Optimalisasi Sistem Informasi pada UMKM Laundry Beladies 
Gambar 3 menampilkan sesi diskusi dari kegiatan ini.

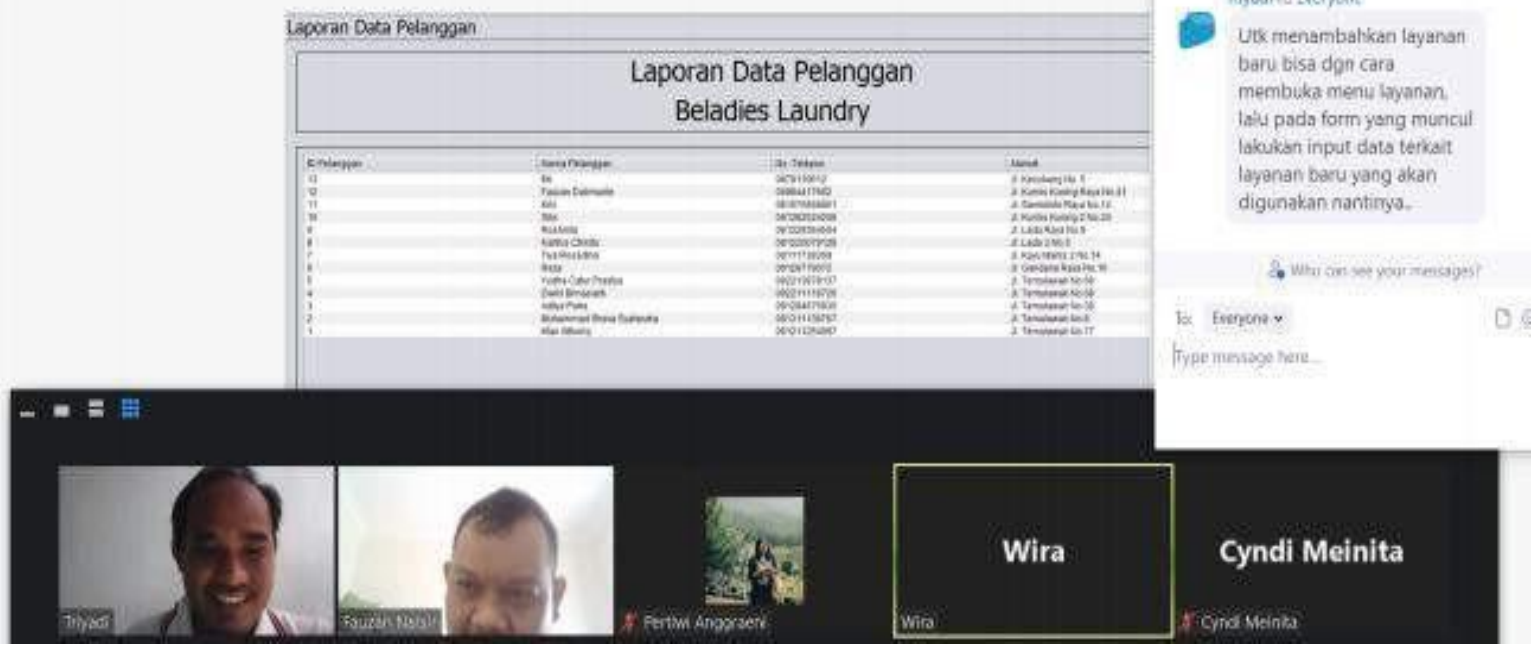

Sumber: Hasil Pelaksanaan (2021)

Gambar 3. Pertanyaan dari Karyawan Beladies Laundry

Gambar 4 menunjukkan sesi diskusi tanya jawab dengan narasumber dalam proses pelaksanaan kegiatan abdimas.

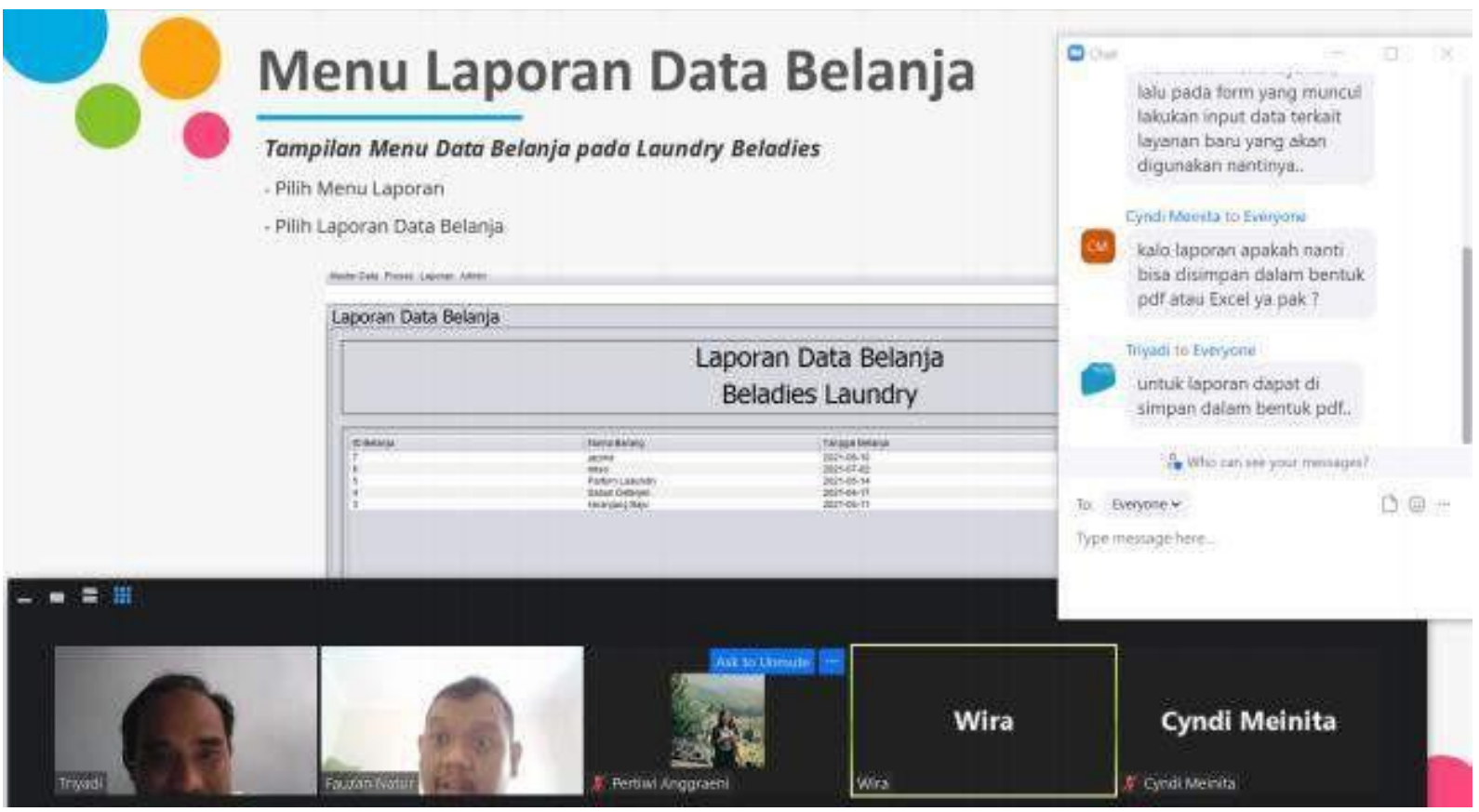

Sumber: Hasil Pelaksanaan (2021)

Gambar 4. Proses tanya jawab 
Kegiatan pengabdian masyarakat pada UMKM Beladies Laundry Kiloan ini mendapat sambutan yang sangat baik. Hasil dari kegiatan pengabdian dapat diketahui bahwa karyawan mendapat pengetahuan terkait pentingnya menggunakan sistem informasi dan dapat menggunakan sistem informasi UMKM Laundry Beladies dengan baik.

\subsection{Tahap Evaluasi Kegiatan}

Tahap evaluasi dilakukan untuk menilai sejauh mana keberhasilan dari kegiatan pelatihan yang telah dilakukan. Hasil evaluasi dapat dijadikan untuk kegiatan selanjutnya. Dalam hal ini, evaluasi dilakukan dengan cara melihat secara langsung manfaat pencatatan transaksi melalui rancangan sistem informasi yang diberikan.

\section{Hasil dan Pembahasan}

\subsection{Lokasi Pengabdian Kepada Masyarakat}

Lokasi kegiatan bertempat di lokasi usaha UMKM Laundry Beladies yang berada di Jl. Raya Poncol, No. 4 RT 009/ RW 009 Ciracas Jakarta Timur.

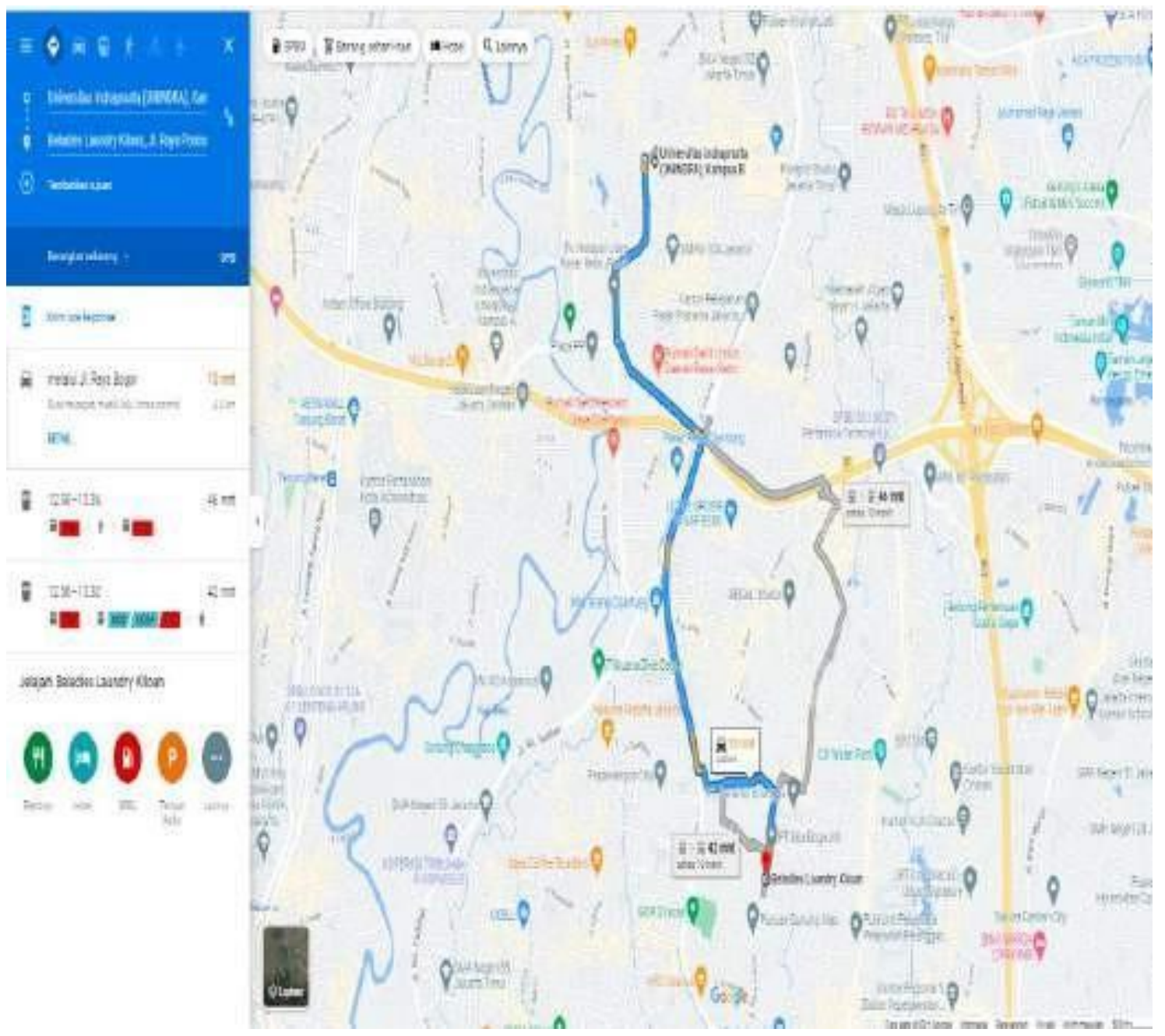

Sumber: Hasil Pelaksanaan (2021)

Gambar 5. Lokasi UMKM Laundry Beladies 


\subsection{Pelaksanaan}

Salah satu tugas dalam Tridarma Perguruan Tinggi adalah pengabdian kepada masyarakat, yang telah kami laksanakan bertempat di UMKM Laundry Beladies Jakarta Timur. Abdimas tersebut mendapat sambutan yang baik dari mitra, dan pelatihan optimalisasi pemanfaatan sistem informasi laundry yang dilakukan oleh Dosen Program Studi Informatika (sebagai pelaksana kegiatan) di hadapan karyawan dan pemilik UMKM Laundry (sebagai mitra/peserta kegiatan) dapat dikatakan berhasil dan terlaksana dengan baik walaupun dilakukan secara online dan dilaksanakan dalam satu kali pertemuan pada hari Senin, 29 November 2021. Link Zoom Meeting: https://us04web.zoom.us/j/74976730251?pwd=REU2Qk1ZeDl1b0t0V3N1WU4vcUhxdz0 9

\section{Join our Cloud HD Video Meeting \\ Zoom is the leader in modern enterprise video communications, with an easy, reliable cloud platform for video and audio conferencing, chat, and webinars across mobile, us04web.zoom.us \\ https://us04web.zoom.us/j/74976730251? pwd=REU2Qk1ZeDl1b0tov3N1WU4vcUhxdz09}

Sumber: Hasil Pelaksanaan (2021)

\section{Gambar 6. Link Zoom Meeting}

Dari hasil abdimas di UMKM Beladies Laundry Kiloan dapat diketahui bahwa dengan adanya sistem informasi Laundry Kiloan tersebut dapat mempermudah karyawan dalam proses transaksi dan proses penyimpanan data dan juga mempermudah dalam laporan yang di butuhkan oleh pemilik usaha UMKM Beladies Laundry Kiloan.

Pelaksanaan abdimas ini bertujuan guna menguji hipotesis yaitu apakah sistem informasi pada UMKM Beladies Laundry Kiloan efektif digunakan oleh karyawan dalam proses transaksi di UMKM tersebut. Hasil dari penelitian menyatakan bahwa sistem informasi pada UMKM Beladies Laundry Kiloan efektif digunakan oleh karyawan. Namun, terdapat kendala yakni sistem informasi hanya dapat digunakan di tempat sistem informasi tersebut di-install dan begitupun juga untuk mengakses laporan yang dibutuhkan oleh pemilik usaha UMKM Laundry harus dilakukan ditempat sistem informasi tersebut di-install. Untuk ke depannya diperlukan langkah-langkah selanjutnya untuk memaksimalkan penggunaan sistem informasi UMKM Laundry Beladies, diantaranya a) Pembaruan-pembaruan baru secara berkala sangat diperlukan pada rentang waktu tertentu dengan tujuan mempermudah penggunaan dan menyempurnakan sistem informasi UMKM laundry tersebut; b) Pelatihan cara menggunakan sistem informasi UMKM beladies laundry terbaru dengan tujuan agar dapat mempermudah karyawan dan pemilik usaha dalam melakukan transaksi. 


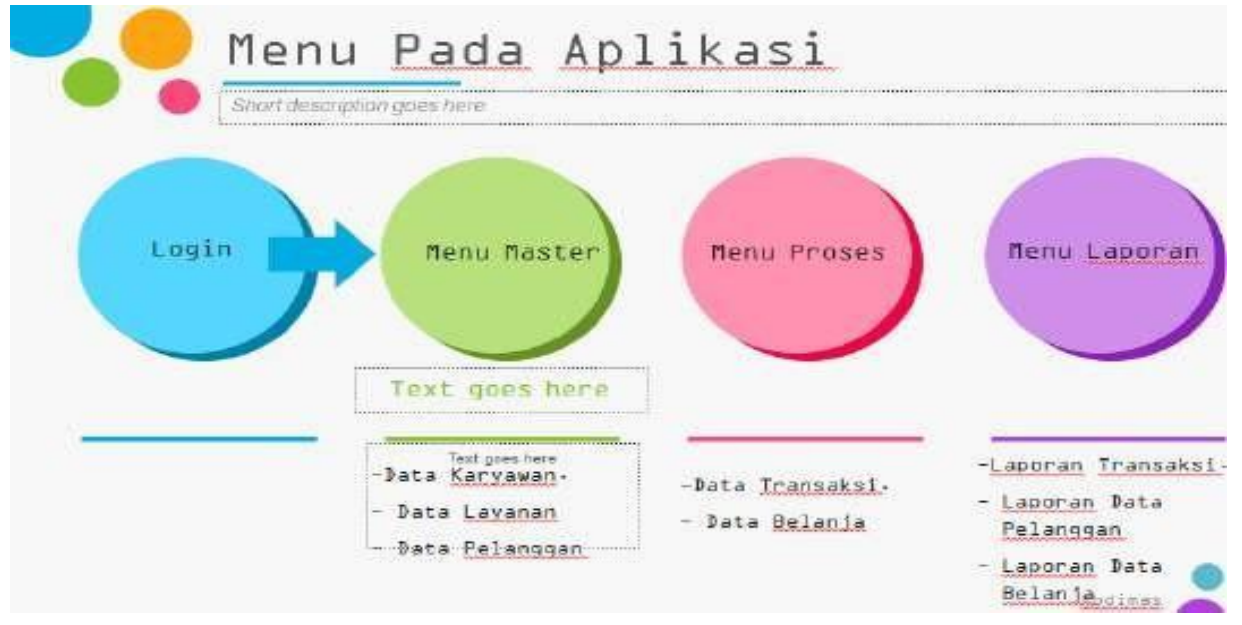

Sumber: Hasil Pelaksanaan (2021)

Gambar 7. PPT Presentasi dan Penjelasan

Gambar 8 menampilkan materi yang dipaparkan oleh narasumber dalam pelaksanaanan kegiatan abdimas.

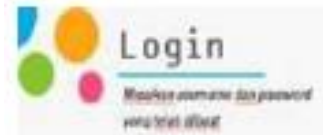
movel iner
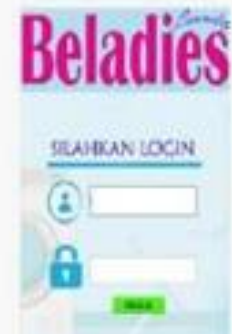

Menu Data Layanan

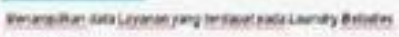
oimive

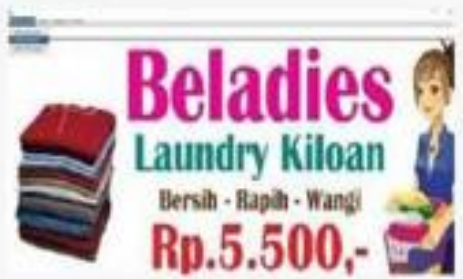

Sumber: Hasil Pelaksanaan (2021)

Gambar 8. PPT Presentasi Menu Pada Aplikasi

Gambar 9 menunjukkan tampilan aplikasi pada halaman laporan data. Pada laporan data dapat dilakukan cetak laporan data karyawan dan cetak laporan data transaksi.

Menu Cetak Laporan Data Karyawan

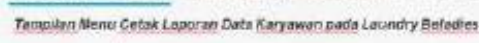

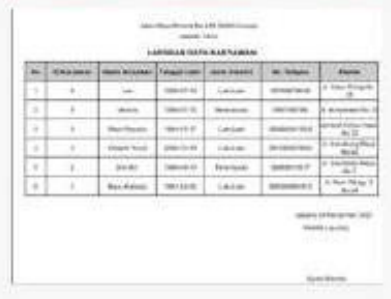

- Menu Cetak Laporan Data Transaksi
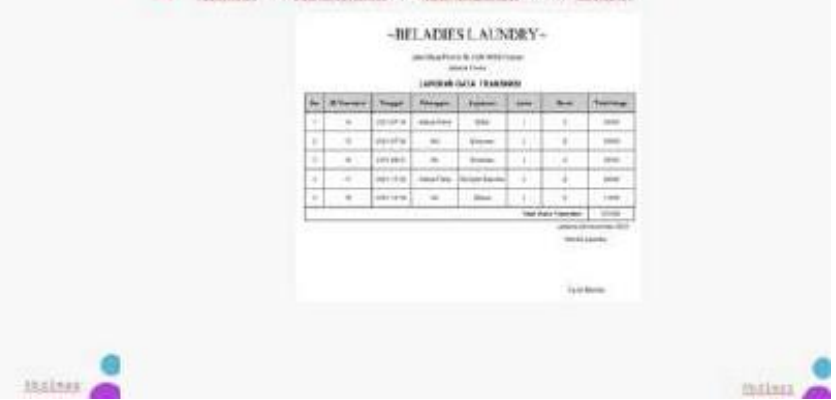

Sumber: Hasil Pelaksanaan (2021)

Gambar 9. Laporan Data 


\section{Kesimpulan}

Setelah berbagai serangkaian yang telah dilakukan dengan analisis dan hasil pengujian sistem informasi pada UMKM Laundry Beladies maka dengan ini dapat disimpulkan beberapa hal sebagai berikut: 1) Proses bisnis pelayanan pelanggan Beladies Laundry belum terkomputerisasi sehingga terdapat permasalahan pada proses pelayanan, di antaranya proses transaksi dan pembuatan laporan yang masih bersifat manual. Dengan dibuatnya sistem terkomputerisasi tersebut diharapkan dapat mengatasi permasalahan yang ada pada jasa laundry Beladies Laundry agar proses bisnis dan pelayanan dapat berjalan lebih baik lagi menggunakan metode Rapid Application Development (RAD); 2) Beladies Laundry belum mempunyai sistem untuk penyimpanan data karyawan, data pelanggan, data layanan, data transaksi, dan data belanja. Dengan adanya sistem yang terkomputerisasi tersebut diharapkan dapat memudahkan admin untuk menyimpan data dan mencari data yang diperlukan; 3) Sistem informasi jasa laundry ini diharapkan dapat membantu admin dalam pembuatan laporan data karyawan, laporan data pelanggan, laporan data layanan, laporan data transaksi dan laporan data belanja serta pembuatan sistem perhitungan biaya beserta notanya.

\section{Daftar Pustaka}

Al Fatta, H. (2007). Analisis dan Perancangan Sistem Informasi Untuk Keunggulan Bersaing Perusahaan dan Organisasi Modern (A. H. Triyuliana, ed.). Yogyakarta: Andi Offset.

AL Fatta, H. (2007). Analisis dan Perancangan Sistem Informasi Untuk Keunggulan Bersaing Perusahaan dan Organisasi Modern (A. H. Triyuliana, ed.). Andi Offset.

Nurul Fitriana, A., Noor, I., \& Hayat, A. (2014). Pengembangan Industri Kreatif Di Kota Batu (Studi Tentang Industri Kreatif Sektor Kerajinan Di Kota Batu). Jurnal Administrasi Publik, 2(2), 281-286.

Rian, H., \& Fuandytama, A. (2019). Pelayanan Jasa Laundry Pada Mamah Laundry and Cleaners Serang. Jurnal Teknologi Informatika Dan Komputer, 5(2), 64-69. https://doi.org/https://doi.org/10.37012/jtik.v5i2.168

Sarosa, S. (2017). Metodologi Pengembangan Sistem Informasi. Jakarta: Indeks.

Simargolang, M. Y., \& Nasution, N. (2018). Aplikasi Pelayanan Jasa Laundry Berbasis WEB (Studi Kasus: Pelangi Laundry Kisaran). Jurnal Teknologi Informasi, 2(1). https://doi.org/https://doi.org/10.36294/jurti.v2i1.402

Sukamto, R. A. (2018). Rekayasa Perangkat Lunak Terstruktur dan Berorientasi Objek. Jurnal Informatika.

Susanto, E., Utami, T. H., \& Hermanto, D. (2019). Sistem Informasi Pemesanan Laundry Berbasis Android $\mathrm{Di}$ Kota Palembang. JATISI, 5(2), 158-168. https://doi.org/https://doi.org/10.35957/jatisi.v5i2.144

Undari, W., \& Lubis, A. sari. (2021). Usaha Mikro Kecil Dan Menengah (Umkm) Dalam Meningkatkan Kesejahteraan Masyarakat. Jurnal Penelitian Pendidikan Sosial Humaniora, 
6(1). https://doi.org/https://doi.org/10.32696/jp2sh.v6i1.702

Widarno, B. (2008). Efektivitas Perencanaan dan Pengembangan Sistem Informasi. Jurnal Akuntasi Dan Sistem Teknologi Informasi, 6(1), 1-13. 